International Review of Research in Open and Distributed Learning Volume 17, Number 3

April - 2016

\title{
Book Review - Doing Q Methodological Research: Theory, Method and Interpretation
}

Watts, S., \& Stenner, P. (2012). Doing Q Methodological Research: Theory, Method and Interpretation. London, UK: Sage. (238 pp.) ISBN 978-1-84920-414-9, £26.99

Review by: Liwen Chen, Ph.D., Graduate Institute of Technology Management, Chung-Hua University, Taiwan, R.O.C.

While the mixed method approach has attracted much attention over the past few years in the field of educational research, including educational technology, Q-methodology, which encapsulates the advantages of both the quantitative and qualitative methods, has not yet entered the mainstream of scholarly educational technology research into human subjectivity and remains unfamiliar to most researchers. Based on more than 16 years of applying Q-methodology in a diverse range of studies, Watts and Stenner's Doing Q Methodological Research is a step-by-step procedure that covers both the theory and pragmatism of gathering, analysing, interpreting, and publishing a Q-study.

This book is proposed to be an invaluable resource for readers on "why" and "how" to undertake Qmethodological research. It contains eight chapters and is divided into three sections. The first two chapters (Section 1) are focused on the basic philosophical and theoretical concepts that underpin the methodology. I found the section on Q-methodology and the quantum theory particularly interesting, although it could have been more persuasive if the similarities and differences between qualitative research and Q-methodology has been emphasised.

The focus of Section 2 (Chapters 3, 4, 5, and 6) is the conduct and delivery of the method using the software. Chapter 3 is devoted to basic research design issues, while the participants, materials and procedures are presented in Chapter 4, and a conceptual and statistical explanation of factor extraction is provided in Chapter 5. Although this section contains well-organised Q-set design issues and detailed examples of text-based Q-statements (i.e., the opinion statements of the research instrument), it could have been more comprehensive if the authors had presented guidelines on how to use pictures, paintings, or even art pieces for the Q-statement design. 
An explanation of factor rotation is provided in Chapter 6, while the focus of Section 3 (Chapters 7 and 8) is factor interpretation. The facilitation of factor interpretation is explained in Chapter 7 , while how to write and publish methodological papers is demonstrated in Chapter 8. The book has three appendices to show readers how to implement factor analyses procedures using PQ Method version 2.11 for Windows, a free Q-methodology software package. Although this section contains a complete overview of factor interpretation, I would have preferred it to have greater coverage and examples of how to give "names" to factors, since most readers will find it difficult to label them.

Apart from McKeown and Thomas's Q Methodology, one of the Quantitative Applications in the Social Sciences series distributed by Sage publications, very few books address Q so distinctively; as a consequence, this is the scholarly work that has been long awaited by the Q-community. Overall, each research method has its own advantages and shortcomings, and this book contains little information on the limitations and drawbacks of Q-methodology. Apart from some minor constraints, this book is meant to encourage both experienced and novice investigators to utilise an 'alternative' mixed method in the context of educational technology.

Athabasca University

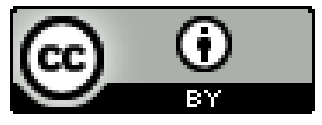

